\title{
Review of the evidence linking protein and energy to mental development
}

\author{
Sally Grantham-McGregor ${ }^{1, *}$ and Helen Baker-Henningham ${ }^{2}$ \\ ${ }^{1}$ Centre for International Child Health, Institute of Child Health, 30 Guilford Street, London, WC1N 1EH, UK: \\ ${ }^{2}$ Department of Educational Studies, University of the West Indies, Mona, Kingston, Jamaica
}

\begin{abstract}
Objective: To examine the evidence as to whether the relationship between undernutrition and poor child development is causal.

Design: Selected studies from developing countries were discussed. Observational studies were first considered then experimental studies of preventative and remedial supplementation. The type of functions affected, the presence of sensitive periods and the role of protein and energy versus that of micronutrients were reviewed.

Results: Childhood undernutrition is generally associated with concurrent and longer term deficits in cognition, behaviour and motor skills, although the relationship is likely to be confounded by socio-economic factors. Supplementation trials have had many design problems. However, those beginning at any age from pregnancy up to 24 months have consistently had concurrent benefits suggesting a causal relationship. Supplement begun in older children had little or no effect, albeit there are too few studies to conclude with confidence. The limited evidence suggests that benefits are more likely to be sustained if supplementation begins in late pregnancy or at birth and is continued until the child is at least 24 months old.

Deficits in cognition tend to be global and there is insufficient evidence of specific deficits. There is some evidence that the first 2 years of life are most sensitive to the effects of undernutrition. Most studies have failed to separate the effects of energy and protein from those of micronutrients. One study showed that energy and/or protein affects children's development. Psychosocial stimulation has had consistent benefits on undernourished childrens' development Conclusions: Public health nutrition programmes should include a component in which children who are at risk are targeted during the first 2 years of life with combined interventions involving nutrition, health care and early stimulation.
\end{abstract}

Keywords Undernutrition Mental development

\section{Introduction}

Undernutrition is currently diagnosed when measures of weight for age, height for age or weight for height are below -2 standard deviations of internationally accepted references ${ }^{1}$. Undernutrition was previously referred to as protein energy malnutrition. However, when children are undernourished due to low dietary intakes of protein and energy their diets are usually also deficient in many micronutrients ${ }^{2}$. There is some evidence linking zinc, iron and iodine deficiencies to poor development and it is likely that other micronutrients also affect development. In addition, in many studies of supplementation with calories and protein, micronutrient supplements were also given. It is therefore usually not possible to separate the effects of macronutrients from those of micronutrients.

Although the prevalence of childhood undernutrition has declined it remains extremely high. It is estimated that $33 \%$ of children under 5 years in developing countries are moderately stunted and 10\% moderately wasted ${ }^{3}$. Since the 1950s, research has been conducted on the effect of undernutrition on children's development and there is now a considerable amount of evidence indicating a causal relationship between undernutrition and poor development. In this report we will review the literature from developing countries concerning the effects of stunting (low height for age) and wasting (low weight for height) as well as studies in which supplements containing protein and energy were given. We first briefly discuss child development and factors which affect development.

\section{Child development and the role of the environment}

It is important to understand child development and the context of undernutrition in order to evaluate the effects of undernutrition. Child development is multi-dimensional and includes cognitive, motor, social and emotional domains, all of which are interdependent with changes in one domain affecting changes in the others. Children's 


\section{2}

development is also multi-determined being influenced by a multitude of factors including genetics, child characteristics (e.g. temperament), the biological state of the child (e.g. health and nutritional status), the proximal environment (e.g. level of stimulation in the home, quality of maternal-child interaction) and the distal environment (e.g. culture, urban-rural residence, type of neighbourhood $)^{4,5}$. Some factors are protective, whereas others make the child more vulnerable, their effects may be additive or interactive. These factors continue to affect development throughout childhood although there may be more sensitive periods and the long-term effects depend on previous, current and future experiences.

\section{Undernourished children's environment}

Undernourished children generally come from disadvantaged backgrounds including such factors as poverty, poor housing and sanitation, poor health care, poor levels of parental education and psychosocial functioning and unstimulating home environments. The children themselves are more likely to have been low birth weight, have frequent infections and other nutrient deficiencies. These factors may independently affect children's development or modify the effects of undernutrition. It is therefore extremely difficult to infer a causal relationship between undernutrition and development from observational studies. There is usually a high probability that unmeasured social and biological variables may confound the relationship. Supplementation trials have many problems but can provide stronger evidence of causal relationships.

\section{Observational studies of undernourished children}

\section{Concurrent cognition and school achievement}

Many observational studies have shown concurrent associations between stunting or low weight for age and poor mental and motor developmental levels in early childhood $^{6-9}$. In later childhood they have shown associations with poor cognition and school achievement ${ }^{10-13}$. Associations between wasting and development are less often found than associations between stunting and development ${ }^{14}$.

In Egypt and Kenya, investigators examined relationships between children's dietary intake and cognition and behaviour. In Egypt, associations were found between children's mental development index and current intake of protein, kcals, and fat at 24 months of age ${ }^{15}$. In Kenya, associations were found between calorie intake at 30 months and amount of vocalisation and play. In addition, intake of kcals, total protein, animal protein and fat between 18 and 23 months and intake of animal protein and fat between 24 and 30 months were associated with cognition at 5 years ${ }^{16}$. However, in studies of dietary intake a large number of tests were often conducted and control for socio-economic background was usually limited.
Sally Grantham-McGregor and Helen Baker-Henningham

\section{Concurrent behavioural differences}

Children hospitalised for severe malnutrition are less active and exploratory, more apathetic and show less active distress in the acute stage than children hospitalised for other diseases ${ }^{17,18}$. They also show reduced orienting response to auditory stimuli ${ }^{19}$, and have low amplitude cries $^{18}$. These behaviours return to normal with recovery except for the quality of exploration. In contrast, the children's level of development usually remains poor.

Moderately undernourished children also show altered behaviour. In young children, these behaviours include lower activity level ${ }^{20}$, lower amounts and less enthusiasm for play and exploration ${ }^{21-24}$, increased fussing ${ }^{21,24,25}$, less positive affect ${ }^{24}$, fewer vocalisations ${ }^{21,9}$, and a tendency to stay closer to the mother ${ }^{26,22,23}$, and be more apathetic ${ }^{27,28}$.

\section{Comment on cross-sectional studies}

Although the findings from cross-sectional studies are generally consistent it is likely that children's disadvantaged home backgrounds confound the relationship between undernutrition and child development. Even when investigators control for several socio-economic background variables it is unlikely that they have taken all possible ones into account. Furthermore, the temporal relationship between undernutrition and poor development is unknown and it remains possible that children with poor development are most likely to become undernourished. Longitudinal studies are more useful as they allow the exploration of changes in development over time and the effect of moderating variables can be examined. However, prospective studies beginning before the onset of undernutrition have rarely been conducted.

\section{Longitudinal studies of undernourished children}

\section{Associations between growth and change in development}

Significant associations have been found between children's linear growth and change in development in Guatemala and Jamaica. Change in height from 6 to 24 months of age was associated with change in development in Guatemalan children ${ }^{29}$. In stunted Jamaican children aged between 6 and 24 months, change in height over the subsequent 24 months was associated with change in developmental levels. Furthermore, change in height in the first 12 months predicted change in mental age in the second 12 months even after controlling for height change in the second year ${ }^{30}$.

\section{Follow-up of children with severe clinical malnutrition in early childbood}

Children hospitalised for severe malnutrition in early childhood in developing countries have been found to have long-term deficits in cognitive development and school achievement up to adolescence. Studies compared previously severely malnourished children with matched 
controls and/or siblings. In eight out of nine studies reviewed using matched controls the previously malnourished children performed significantly worse on cognitive tests than children without a history of malnutrition ${ }^{31-39}$. Only one study, in South Africa, ${ }^{40}$ showed no difference between the groups. Deficits were present up to puberty but there is little data from adults. There is some suggestion that stunting or weight for age in the acute stage is more predictive of later function than wasting or the presence of oedema.

Studies using siblings as a comparison group have produced less consistent results. Siblings of previously malnourished children performed significantly worse on intelligence tests than their siblings in Mexico ${ }^{41}$, Jamaica $^{36,42}$, Lebanon ${ }^{43}$, and Nigeria ${ }^{38}$. A study in South Africa $^{44}$ showed no difference on an intelligence test between the groups although the index children did perform worse than their siblings on a drawing test. When school grades have been used as the outcome measure differences were less likely to be found. One study found significantly worse school grades in the previously malnourished group ${ }^{45}$ whereas in two other studies no differences were found ${ }^{46,47}$. Although comparisons with siblings ensure children are matched for social background and family characteristics, the siblings are likely to have suffered from moderate malnutrition themselves.

Generally there was no association between level of function and age of admission to hospital, which ranged from the first 6 to 36 months.

\section{Follow-up studies of children with stunting in early childbood}

We found five longitudinal studies of children, who were stunted in early childhood. In all studies, early stunting was associated with cognitive or school achievement deficits at follow-up at varying ages from 5 years to adolescence $^{16,48-51}$. The age of recorded stunting was 12 months $^{50}, 9-24$ months $^{51}, 18-30$ months $^{16}, 3$ years $^{48}$, and 24 months ${ }^{49}$.

\section{Type of long-term cognitive and motor deficits}

Most follow-up studies of school-aged children who suffered from early childhood severe clinical malnutrition used global measures. The children usually had lower IQs and poorer school achievement than matched peers. When cognitive functions were examined, different functions were examined in different studies. Few studies examined a comprehensive range of cognitive functions. There is therefore insufficient evidence to identify specific cognitive deficits. However, where reasoning and perceptual-spatial functions were examined they were fairly consistently affected ${ }^{31,38,39}$ as was fine motor function. Soft neurological signs have been found and in younger children intersensory integration and performance on Piagetian tests were affected.
Children who were stunted in the first 3 years of life have also shown deficits in later childhood in a broad range of measures and there is no consistent evidence of a specific cognitive deficit. In Guatemala ${ }^{48}$, early stunting was associated with deficits in literacy, numeracy, general knowledge and maximum school grade reached at 18 years or older in both sexes and reasoning (Ravens matrices) in boys only. In Jamaica ${ }^{51}$, at 11-12 years of age, deficits were found in a wide range of cognitive and school achievement tests including IQ, reading, arithmetic, reasoning, vocabulary, verbal analogies, visualspatial working memory, simple and complex auditory working memory, sustained attention and information processing. Out of the range of cognitive tests, only simple auditory working memory was not affected. In an earlier Jamaican study, stunting before 2 years of age was related to later deficits in school achievement ${ }^{50}$. In the Philippines $^{49}$, early stunting was associated with low IQ and school drop out, grade repetition and absenteeism at 11 years. In Kenya ${ }^{16}$, early height and weight were associated with children's vocabulary and reasoning (Raven's matrices) at 5 years.

\section{Long-term behavioural effects}

There is limited evidence that some behavioural anomalies persist until later childhood and adolescence. Jamaican children who were stunted before 2 years of age were found to be more inhibited and less attentive at age 8-10 years $^{52}$, and had more conduct disorders at age 11-12 years ${ }^{53}$. Children hospitalised for malnutrition in the first year of life were found to have poorer behaviour in school including attention deficits, poor social skills and were more aggressive and more distractible at home than children with no history of malnutrition ${ }^{54}$. Children around 4 years of age were observed to play less and stay closer to their mothers and be more unresponsive when given a task ${ }^{26}$. In the quasi-experimental study in Guatemala, children were classified into two groups (high supplementation and low supplementation) according to the level of maternal supplementation during pregnancy and child supplementation from birth to 4 years. Children in the high supplementation group were more exploratory, more persistent, more involved and active, less anxious and displayed more affective expression (both positive and negative) in a range of structured and unstructured situations ${ }^{55,56}$.

\section{Comments on longitudinal studies}

The majority of long-term follow-up studies of undernourished children in developing countries have found some cognitive, fine motor or behavioural deficits in later childhood. This finding applies to both children who were stunted and those who had severe malnutrition and were admitted to hospital. There was little consistent evidence of specific cognitive deficits. However, the risk factors 
1194

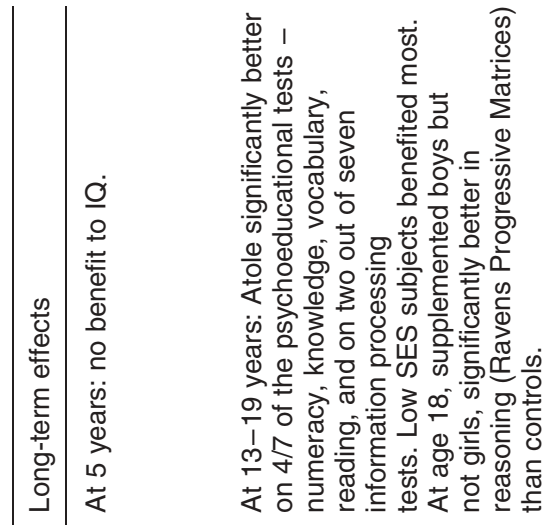

Sally Grantham-McGregor and Helen Baker-Henningham

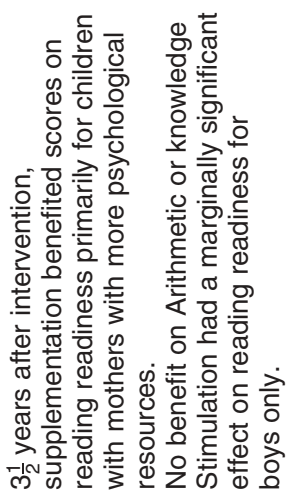

\section{홍}

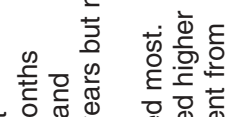

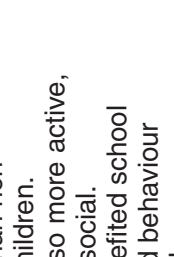

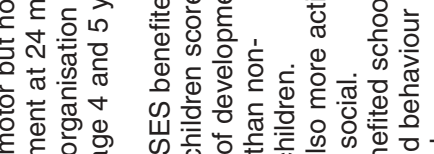

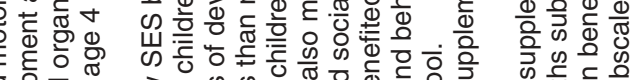

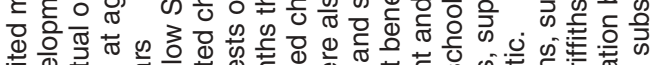

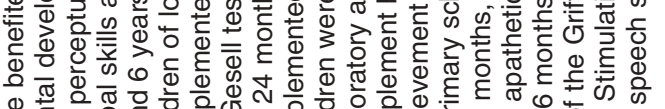

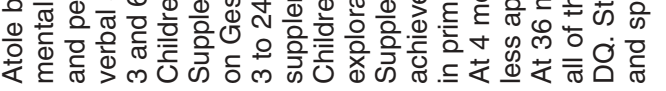
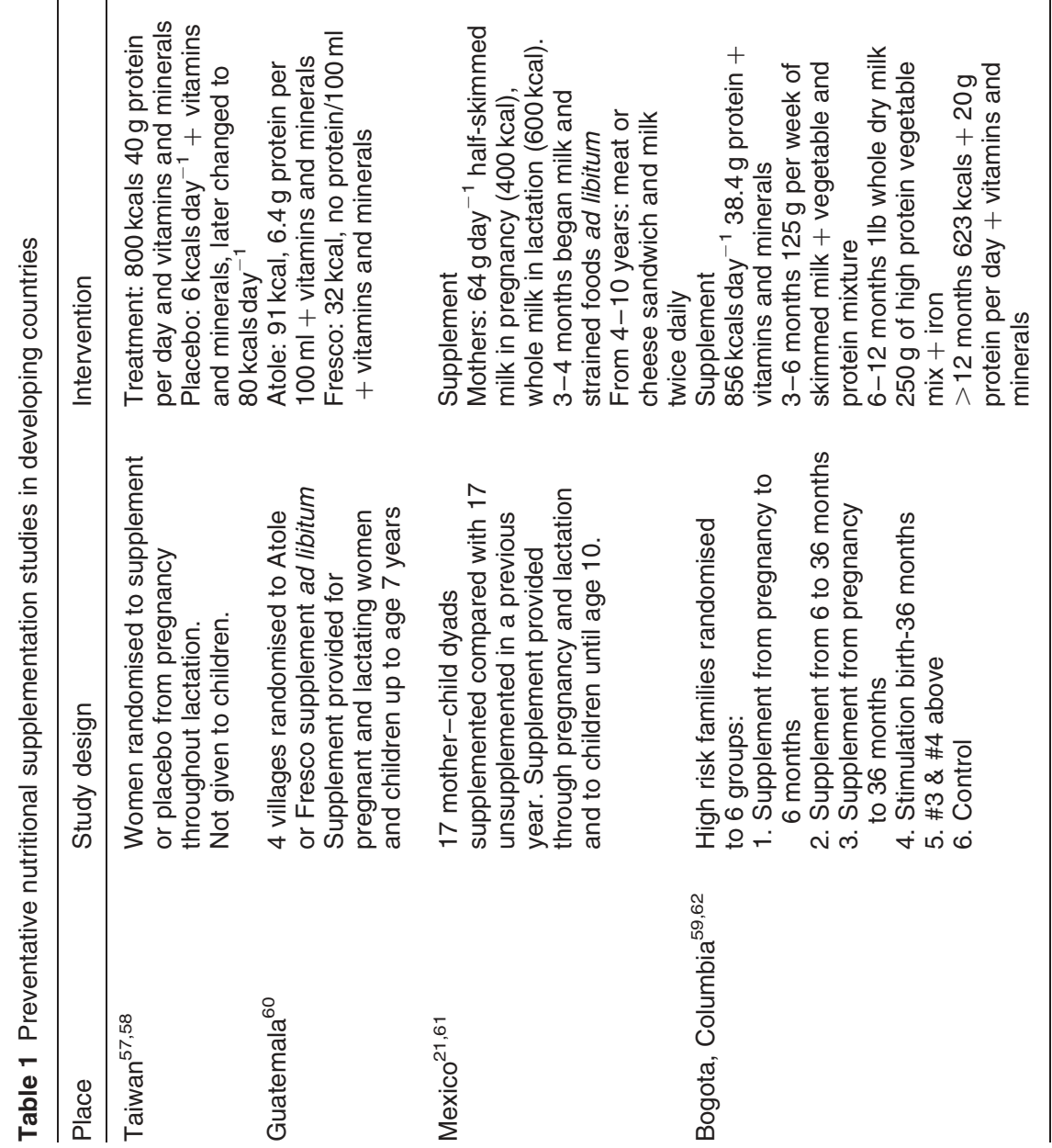


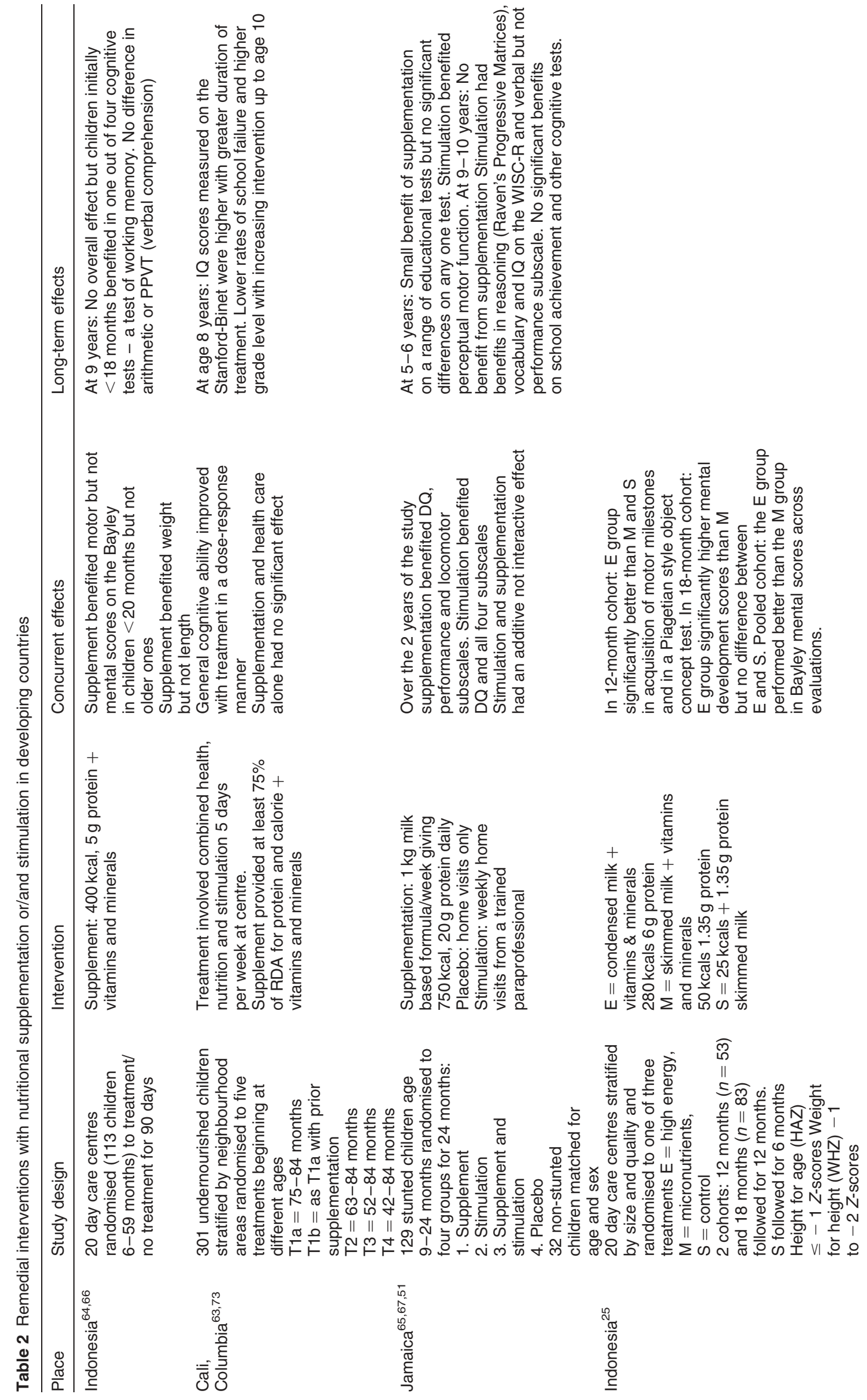


associated with poverty confounding the results remain a possibility. There is very little data from adulthood.

\section{Intervention studies}

There are several supplementation studies, which had developmental outcomes and these should allow causal inferences. They may be divided into preventative ones, which began in pregnancy or at birth and remedial ones, which targeted children who are already undernourished. A few studies also included stimulation. The details of the more important studies are given in Tables 1 and 2 .

\section{Preventive supplementation}

One study, a randomised trial in Taiwan ${ }^{57}$, involved supplementation of high risk women in pregnancy and lactation only. Their infants were not supplemented. At 8 months of age, benefits were found to children's motor but not mental development but there was no evidence of a sustained benefit on their IQ at 5 years ${ }^{58}$. In populations at risk for undernutrition, supplementation in pregnancy followed by supplementation of children for at least 2-3 years has consistently had concurrent benefits on children's development. These studies were conducted in Bogota ${ }^{59}$, Mexico ${ }^{21}$, and Guatemala ${ }^{60}$. Long-term benefits were found in Mexico ${ }^{61}$ and Guatemala. The follow-up in Bogota is not reported in detail but children at 7 years showed benefits in reading readiness ${ }^{62}$.

However, there were problems with the study design in some of the preventative supplementation trials. In Mexico, the groups were very small and were not randomly assigned to treatment but were separated by time. In the Guatemalan study, only four villages were used in the randomisation and differences were found between the villages on key characteristics such as paternal occupation and literacy and quality of schooling. Only in Taiwan was a true placebo given. In addition, as all of the studies involved supplementation of mothers, it is unclear if the benefits to the children can be ascribed to the supplement per se or are due to changes in maternal behaviour.

\section{Remedial supplementation}

The effects of remedial interventions for undernourished children are less consistent. In one study in which supplementation began after age 3 years, the children showed no concurrent or long-term benefits from supplementation alone ${ }^{63}$. Three studies involved supplementation of children before the age of 24 months and concurrent benefits were obtained. Two of these studies were conducted in Indonesia ${ }^{25,64}$, and one was in Jamaica $^{65}$. Two of the studies have reported long-term follow-up. In Indonesia, some benefit was sustained at 9 years of age but only for children supplemented before the age of 18 months and in one of several tests ${ }^{66}$. In Jamaica small global benefits were found at age $7-8$ years ${ }^{67}$, but 
benefits were not sustained at age 11-12 years ${ }^{51}$. Preventative $^{68}$ or remedial supplementary feeding tended to benefit motor performance before mental development. It may be that only motor performance is affected in the first year of life or it is easier to detect on the tests used at this age. However, there is evidence that motor development is affected first and then the benefits spread to other areas of development. For example, in the study with stunted children in Jamaica $^{65}$, supplementation only benefited motor development in the 1st year but in the 2nd year benefits were also found on the performance subscale. In two other studies, benefits of supplementation were first found for locomotor and manipulative activities and later gains were found in other areas ${ }^{28,69}$.

\section{Conclusion from nutritional supplementation studies}

Supplementation beginning at any age from pregnancy up to 24 months has had concurrent benefits. Supplement begun in older children had little effect, albeit there were too few studies to conclude with confidence. The limited evidence from long-term follow-up studies suggests that supplementation is more likely to be sustained if begun in late pregnancy and continued with the child for at least the first 24 months.

\section{Evidence of sensitive periods}

Evidence from longitudinal observational studies or supplementation trials can give some indication of whether there is a period of development, which is most sensitive to nutritional insults.

\section{Observational studies}

Observational studies have shown that undernutrition at any time in the first 36 months of age is usually associated with long-term effects. In the Jamaican study with stunted children, their height, weight and head circumference were measured on enrolment between 9-24 months, 2 years later and at 7 and 11 years of age $\mathrm{e}^{70}$. Height on enrolment and head circumference on enrolment and 2 years later predicted IQ at 11 years. None of the anthropometric measurements taken at 7 and 11 years of age predicted IQ. These results suggest that children under 2-3 years of age are more sensitive to the effects of undernutrition and thus reinforce the importance of early childhood.

\section{Evidence from supplementation studies}

Supplementation studies should give more precise estimates of sensitive periods. Several studies examined the effect of early versus later supplementation. In Bogota $^{59}$, no significant benefit was found at 3 years of age from supplementation of the mothers in pregnancy and the children up to 6 months of age. Also there was no significant difference between the groups treated from pregnancy to 36 months or from age 6 months to 3 years.

In Guatemala ${ }^{60}$, a group supplemented from pregnancy through to at least 2 years showed benefits in more tests than children receiving treatment after the age of 2 years. Similarly in Indonesia ${ }^{64}$, children under 20 months benefited from supplement, but not older children.

\section{Duration and severity of undernutrition}

Duration and severity of undernutrition may also play a role. In Ethiopia, children whose weights fell below the 3 rd centile of the NCHS references by 4 months of age had poorer developmental levels at 24 months than children whose weights fell below by 10 or 12 months. However, when weight at 2 years of age was controlled, the groups were not different. Both groups had poorer development than children whose weights were never below the $3 \mathrm{rd}$ centile at these ages $^{71}$. Similarly, in the Philippines ${ }^{49}$, children who became stunted by 6 months of age had poorer levels of IQ scores at 11 years than children who became stunted by 24 months. However, when severity of stunting at 24 months was considered, early stunting was no longer significant.

\section{Summary of evidence of vulnerable periods}

The findings from the above supplementation studies indicate that supplementation in pregnancy alone, with or without the first 6 months has concurrent but no sustained benefit. Supplementation in the last trimester of pregnancy and for the first 2-3 years results in concurrent and probably sustained benefits.

When supplementation begins in already undernourished children, concurrent benefits usually occur if they are 2 years of age or younger. The evidence is insufficient to determine whether benefits are sustained. It is unknown whether supplementing children over 3 years produces benefits. The data are insufficient to come to firm conclusions but they point to the first 2 years being the most important.

\section{Stimulation}

Studies involving stimulation (with or without supplementation) with undernourished children have generally been successful with most producing concurrent benefits $^{59,63,65,72}$. We found three studies which followed up the children and long-term benefits were present in all ${ }^{51,72,73}$. The study in Bogota reported above ${ }^{59}$ showed only limited concurrent benefits of stimulation and $3 \frac{1}{2}$ years following the end of intervention the boys only showed a marginal benefit in reading ${ }^{62}$. The children were younger than in the other studies and it is difficult to ascertain if lack of benefit was due to inappropriate intervention or to younger children being less responsive to stimulation. 


\section{Activity and undernutrition}

Undernourished children have been observed to be less active than better nourished children in several studies. Undernourished children in Uganda were less active than adequately nourished expatriate children ${ }^{74}$ although cultural differences may account for this finding. Guatemalan children with low weight for height were less active than children with higher weights for height ${ }^{75}$. However, a study in Columbia found no evidence of undernourished children (age 6-16 years) expending less energy as measured by heart rates and metabolic rates ${ }^{76}$.

Supplementation studies have mixed results. Children recently recovered from severe malnutrition were found to have reduced energy expenditure ${ }^{77}$ and reduced activity levels ${ }^{78}$ when energy intakes were reduced in a clinical setting. In the supplementation study in Mexico, children in the supplemented group were more active than nonsupplemented children ${ }^{21}$. However, in the Jamaican study with stunted children, supplementation had no effect on activity level ${ }^{20}$. In the recent Indonesian study, supplemented children in the 12-month cohort, showed increased activity levels compared to the placebo group although children in the 18-month cohort did not ${ }^{79}$.

Both the Jamaican and Indonesian studies showed that activity was highly related to motor development in the very young undernourished children and less so as they got older. Thus reduced activity may be partly a reflection of delayed motor maturation at this age.

\section{Possible mechanisms linking undernutrition to poor development}

One theory linking undernutrition to poor development is the functional isolation hypothesis ${ }^{80}$. In this theory, the behavioural characteristics of undernourished children (reduced activity, exploration and apathy) lead to reduced interaction with the environment and this in turn leads to poor developmental outcomes. In addition, caregivers have been found to be less stimulating towards undernourished children although it is unclear whether the caretakers' behaviour precedes the development of undernutrition $^{32}$, or is a reaction to the behaviour of undernourished children ${ }^{21}$. Undernutrition may also result in structural and functional impairment to the brain and central nervous system ${ }^{81}$ that affects development. A less well established hypothesis is that undernourished children have an altered response to stressors ${ }^{52}$ and this in turn may affect function.

\section{Studies differentiating protein and energy from micronutrients}

It is often difficult to separate macronutrients from micronutrients in the above studies. In some supplementation studies, micronutrients were given as well as food and the controls received nothing. For example, in Colombia $^{59}$, the supplemented group was given ferrous sulphate and vitamin A as well as food and in Mexico ${ }^{21}$, the supplemented group also received micronutrients. In both studies the controls were not supplemented. Also in Jamaica $^{82}$, the supplemented group received milk formula, which was fortified with micronutrients.

In Indonesia ${ }^{64}$, no micronutrients were given to either group so the supplemented group only received the micronutrients naturally present in the food. In Taiwan ${ }^{57}$, both supplemented and placebo groups received micronutrients but it is not clear if they received the same amounts.

In Guatemala ${ }^{60}$, investigators attempted to separate protein and energy from micronutrients and villages were randomised to receive Atole (protein and energy with micronutrients) or Fresco (micronutrients alone). The Atole group showed concurrent and long-term benefits over the Fresco group. However, differential rates of consumption favouring the Atole group were found in early childhood and hence different amounts of micronutrients were consumed.

A recent Indonesian study of supplementing undernourished children ${ }^{25}$ was probably the only study to adequately separate micronutrients from milk based supplement. Children were randomised to group E, which received condensed milk with micronutrients $(6 \mathrm{~g}$ protein and $280 \mathrm{kcals}$ per $100 \mathrm{ml}$ ), group M, which received skimmed milk and micronutrients $(50 \mathrm{kcals}$ and $1.35 \mathrm{~g}$ protein) or group $\mathrm{S}$, which received skimmed milk alone ( $25 \mathrm{kcals}$ and $1.35 \mathrm{~g}$ protein). In the cohort enrolled at 12 months of age, children in the E group showed significant benefits in motor milestones and a test of searching for objects compared with the $M$ group. However, the micronutrient group showed benefits compared with the $\mathrm{S}$ group and both $\mathrm{E}$ and $\mathrm{M}$ were better than $S$ in the motor and mental development index of the Bayley Scales.

In the 18-month cohort, the E supplement showed significant benefits compared with the M group in mental development index of the Bayley Scales.

\section{Summary}

Only the Indonesian study managed to isolate energy and protein from micronutrients and therefore there is limited evidence that energy and/or protein alone affects children's development.

\section{Conclusions}

There is ample evidence that undernourished children's development, behaviour and school achievement is usually poor both concurrently and in the long term. Supplementation studies in children under 3 years have consistently shown concurrent benefits to child development. These studies are from different countries and some have design 
problems, however, the consistency of the finding suggests that the relationship is causal. There is very limited evidence that benefits from supplement are sustained if supplement is begun from pregnancy or birth. There is considerable evidence that the first 2 years are the most sensitive to undernutrition. The data is too limited to separate the role of protein and calories from that of micronutrients with confidence although one study showed benefits from energy and protein. Not surprisingly, it appears that for optimal development children need a well balanced diet. It is also clear that undernourished children need an enriched environment to maximise their future development.

\section{References}

1 Hamill P, Drizd T, Johnson C, Reed R, Roche A. NCHS growth curves for children birth to 18 years. United States: US DHEW Pub No (PHS) 78-1650, Series II, No. 165, 1977.

2 Schurch B. Malnutrition and behavioural development: the nutrition variable. Journal of Nutrition 1995; 125(Suppl. 8): S2255-62.

3 UNICEF. The State of the World's Children. Oxford: Oxford University Press, 2001.

4 Grantham-McGregor S, Pollitt E, Wachs T, Meisels S, Scott K. Summary of the scientific evidence on the nature and determinants of child development and their implications for programmatic interventions with young children. Food and Nutrition Bulletin 1999; 20: 4-6.

5 Wachs T. Necessary but not sufficient. The Respective Roles of Single and Multiple Influences on Individual Development. Washington, DC: American Psychological Association, 2000.

6 Lasky R, Klein R, Yarbrough C, Engle P, Lechtig A, Martorell R. The relationship between physical growth and infant behavioural development in rural Guatemala. Child Development 1981; 52: 219-26.

7 Monckeberg F. Malnutrition and mental capacity. Pan American Health Organization, ed. Nutrition, the Nervous System and Behaviour. Scientific Publication No. 251. Washington DC: PAHO, 1972, 48-54.

8 Powell C, Grantham-McGregor S. The ecology of nutritional status and development in young children in Kingston, Jamaica. American Journal of Clinical Nutrition 1985; 41: 1322-31.

9 Sigman M, Neumann C, Baksh M, Bwibo N, McDonald M. Relationship between nutrition and development in Kenyan toddlers. Journal of Pediatrics 1989; 115: 357-64.

10 Clarke N, Grantham-McGregor S, Powell C. Nutrition and health predictors of school failure in Jamaican children. Ecology of Food and Nutrition 1991; 26: 1-11.

11 Florencio C. Nutrition, Health and Other Determinants of Academic Achievement and School-related Behaviour of Grades One to Six Pupils. Quezan City: University of the Phillipines, 1988.

12 Moock P, Leslie J. Childhood malnutrition and schooling in the Teri region of Nepal. Journal of Development Economics 1986; 20: 33-52.

13 Sigman M, Neumann C, Jansen A, Bwibo N. Cognitive abilities of Kenyan children in relation to nutrition, family characteristics, and education. Child Development 1989; 60: $1463-74$.

14 Grantham-McGregor S. A review of studies of the effects of severe malnutrition on mental development. Journal of Nutrition 1995; 125: S2233-8.

15 Wachs T, Moussa W, Bishry Z, Yunis F, Sobhy A, McCabe G, Jerome N, Gallal O, Harrison G, Kirksey A. Relations between nutrition and cognitive performance in Egyptian toddlers. Intelligence 1993; 17: 151-72.

16 Sigman M, McDonald M, Neumann C, Bwibo N. Prediction of cognitive competence in Kenyan children from toddler nutrition, family characteristics and abilities. Journal of Child Psychology and Psychiatry, and Allied Disciplines 1991; 32: 307-20.

17 Grantham-McGregor S, Stewart M, Powell C. Behaviour of severely malnourished children in a Jamaican hospital. Developmental Medicine and Child Neurology 1991; 33: 706-14.

18 Lester B. Spectrum analysis of the cry sounds of well nourished and malnourished infants. Child Development 1976; 47: 237-41.

19 Lester B. Cardiac habituation of the orienting response to an auditory signal in infants of varying nutritional status. Developmental Psychology 1975; 2: 432-42.

20 Meeks-Gardner J, Grantham-McGregor S, Chang S. Activity and behavioural development in stunted and non-stunted children and response to nutritional supplementation. Child Development 1995; 66: 1785-97.

21 Chavez A, Martinez C. Growing Up in a Developing Community. Guatemala City: Institute of Nutrition in Central America and Panama, 1982.

22 Graves P. Nutrition, infant behaviour, and maternal characteristics: a pilot study in West Bengal, India. American Journal of Clinical Nutrition 1976; 29: 305-19.

23 Graves P. Nutrition and infant behaviour: a replication study in the Katmandu Valley, Nepal. American Journal of Clinical Nutrition 1978; 31: 541-51.

24 Meeks-Gardner J, Grantham-McGregor S, Himes J, Chang S. Behaviour and development of stunted and non-stunted Jamaican children. Journal of Child Psychology and Psychiatry, and Allied Disciplines 1999; 40: 819-27.

25 Pollitt E, Saco-Pollitt C, Jahari A, Husaini M, Huang J. Effects of an energy and micronutrient supplement on mental development and behaviour under natural conditions in undernourished children in Indonesia. European Journal of Clinical Nutrition 2000; 54(Suppl. 2): S80-90.

26 Grantham-McGregor S, Schofield W, Haggard D. Maternal child interaction in survivors of severe malnutrition who received psychosocial stimulation. European Journal of Clinical Nutrition 1989; 43: 45-52.

27 Allen L. The nutrition CRSP: what is marginal malnutrition, and does it affect human function? Nutrition Review 1993; 51: $255-67$.

28 Mora J, Clement J, Christiansen N, Ortiz N, Vuori L, Wagner M. Nutritional supplementation, early stimulation and child development. In: Brozek J, Schurch B, eds. Behavioural Effects of Energy and Protein Deficits. DHEW Publication no. 79-1906. Washington DC: US Department of Health, Education and Welfare, 1979, 225-69.

29 Lasky R, Klein R, Yarbrough C, Engle P, Lechtig A, Martorell R. The relationship between physical growth and infant behavioural development in rural Guatemala. Child Development 1981; 52: 219-26.

30 Powell C, Walker S, Himes J, Fletcher P, GranthamMcGregor S. Relationships between physical growth, mental development and nutritional supplementation in stunted children: the Jamaican study. Acta Paediatrica 1995; 84: 22-9.

31 Champakam S, Srikantia S, Gopalan C. Kwashiorkor and mental development. American Journal of Clinical Nutrition 1968; 21: 844-52.

32 Cravioto J, Delcardie E. Microenvironmental factors in severe protein calorie malnutrition. In: Scrimshaw N, Behar M, eds. Nutritional Agricultural Development. New York: Plenum Publishing Corporation, 1976, 25-36.

33 Hoorweg J, Stanfield J. The effects of protein-energy malnutrition in early childhood on intellectual and motor 
abilities in later childhood and adolescence. Developmental Medicine and Child Neurology 1976; 18: 330-50.

34 Galler J, Ramsey F, Solimano G. The influence of early malnutrition on subsequent behavioural development. III Learning disabilities as a sequel to malnutrition. Pediatric Research 1984; 18: 309-13.

35 Galler J, Ramsey F, Forde V. A follow up study of the influence of early malnutrition on subsequent development IV. Intellectual performance in adolescence. Journal of Nutrition Education and Behaviour 1986; 3: 211-22.

36 Richardson S, Birch H, Hertzig M. School performance of children who were severely malnourished in infancy. American Journal of Mental Deficiency 1979; 77: 623-32.

37 Grantham-McGregor S, Schofield W, Powell C. Development of severely malnourished children who received psychosocial stimulation: six-year follow-up. Pediatrics 1987; 79: 247-54.

38 Nwuga V. Effect of severe kwashiorkor on intellectual development among Nigerian children. American Journal of Clinical Nutrition 1977; 30: 1423-30.

39 Hoorweg J. Protein-Energy Malnutrition and Intellectual Abilities: A Study of Teen-Age Ugandan Children. Mouton: S. Gravenhage Parijs, 1976.

40 Bartel P, Griesel R, Burnett L, Freiman I, Rosen E, Geefhuysen J. Long-term effects of kwashiorkor on psychomotor development. South African Medical Journal 1978; 53: 360-2.

41 Birch H, Pineiro C, Alcalde E, Toca T, Cravioto J. Relation of kwashiorkor in early childhood and intelligence at school age. Pediatric Research 1971; 5: 579-85.

42 Hertzig M, Birch H, Richardson S, Tizard J. Intellectual levels of school children severely malnourished during the first two years of life. Pediatrics 1972; 49: 814-24.

43 McLaren D, Yatkin U, Kannawati A, Sabbagh S, Kadi Z. The subsequent mental and physical development of rehabilitated marasmic infants. Journal of Mental Deficiency Research 1973; 7: 273-81.

44 Evans D, Moodie A, Hansen J. Kwashiorkor and intellectual development. South African Medical Journal 1971; 45 1413-26.

45 Pereira S, Sundararaj R, Begum A. Physical growth and neurointegrative performance of survivors of protein-energy malnutrition. British Journal of Nutrition 1979; 42: 165-71.

46 Graham G, Adrianzen B. Status of school of Peruvian children severely malnourished in infancy. In: Brozek J, ed. Behaviour Effects of Energy and Protein Deficits. Washington: US Department of Health, Education and Welfare NIH, 1979 pub No. 79-1906, 185-94.

47 Moodie A, Bowie M, Mann M, Hansen J. A prospective 15 year follow-up study of kwashiorkor patients. Part 11. Social circumstances, educational attainment and social adjustment. South African Medical Journal 1980; 58: 577-681.

48 Martorell R, Rivera J, Kaplowitz J, Pollitt E. Long term consequences of growth retardation during early childhood. In: Hernandez M, Argenta J, eds. Human Growth: Basic and Clinical Aspects. Amsterdam: Elsevier, 1992, 143-9.

49 Mendez M, Adair L. Severity and timing of stunting in the first two years of life affect performance on cognitive tests in late childhood. Journal of Nutrition 1999; 129: 1555-62.

50 Richardson S. Severity of malnutrition in infancy and its relation to later intelligence. In: Brozek J, ed. Behavioural Effects of Energy and Protein Deficits. Washington DC: National Institute of Arthritis, Metabolism, and Digestive Diseases, US Department of Health, Education and Welfare, 1979, 172-84.

51 Walker S, Grantham-McGregor S, Powell C, Chang S. Effects of stunting in early childhood on growth, IQ and cognition at age 11-12 years and the benefits of nutritional supplementation and psychological stimulation. Journal of Pediatrics 2000; 137: 36-41.
52 Fernald L, Grantham-McGregor S. Stress response in school age children who have been growth retarded since early childhood. American Journal of Clinical Nutrition 1998; 68 : 691-8

53 Chang S, Walker S, Grantham-McGregor S, Powell C. Early stunting and later behaviour and school achievement. Journal of Child Psychology and Psychiatry, and Allied Disciplines 2002; 43: 775-83.

54 Galler J, Ramsey F. A follow up study of the influence of early malnutrition on development: behaviour at home and at school. Journal of the American Academy of Child and Adolescent Psychiatry 1989; 28: 254-61.

55 Barrett D, Radke-Yarrow M, Klein R. Chronic malnutrition and child behaviour. Effects of caloric supplementation on social and emotional functioning at school age. Developmental Psychology 1982; 18: 541-56.

56 Barrett D, Radke-Yarrow M. Effects of nutritional supplementation on children's responses to novel, frustrating and competitive situations. American Journal of Clinical Nutrition 1985; 42: 102-20.

57 Joos S, Pollitt E, Mueller W, Albright D. The Bacon Chow study: maternal nutritional supplementation and infant behavioural development. Child Development 1983; 54: 669-76.

58 Hsueh A, Meyer B. Maternal dietary supplementation and 5 year old Stanford Binet IQ test on the offspring in Taiwan. Federation Proceedings 1981; 40: 897.

59 Waber D, Vuori-Christiansen L, Ortiz N, Clement J, Christiansen N, Mora J, Reed R, Herrera M. Nutritional supplementation, maternal education, and cognitive development of infants at risk of malnutrition. American Journal of Clinical Nutrition 1981; 34: 807-13.

60 Pollitt E, Gorman K, Engle P, Martorell R, Rivera J. Early supplementary feeding and cognition. Monographs of the Society for Research in Child Development 1993; 58: 235.

61 Chavez A, Martinez C, Soberanes B, Dominguez L, Avila A Early Nutrition and Physical and Mental Development in Mexican Rural Adolescent Families. Washington, DC: International Center for Research on Women, 1994.

62 Super C, Herrera M, Mora J. Cognitive Outcomes of Early Nutritional Intervention in the Bogota Study. Seattle: Abstracts of the meeting of the Society for Research in Child Development, 1991.

63 McKay H, Sinisterra L, McKay A, Gomez H, Lloreda P. Improving cognitive ability in chronically deprived children. Science 1978; 200: 270-8.

64 Husaini M, Karyadi L, Husaini Y, Sandjaja, Karyadi D, Pollitt E. Developmental effects of short-term supplementary feeding in nutritionally-at-risk Indonesian infants. American Journal of Clinical Nutrition 1991; 54: 799-804.

65 Grantham McGregor S, Powell C, Walker S, Himes J. Nutritional supplementation, psychosocial stimulation, and mental development of stunted children: the Jamaican Study. Lancet 1991; 338: 1-5.

66 Pollitt E, Watkins W, Husaini M. Three-month nutritional supplementation in Indonesian infants and toddlers benefits memory function 8 y later. American Journal of Clinical Nutrition 1997; 66: 1357-63.

67 Grantham-McGregor S, Walker S, Chang S, Powell C. Effects of early childhood supplementation with and without stimulation on later development in stunted Jamaican children. American Journal of Clinical Nutrition 1997; 66: 247-53.

68 Pollitt E, Oh S. Early supplementary feeding, child development and health policy. Food and Nutrition Bulletin 1994; 15: 208-14

69 Klein R. Malnutrition and human behaviour: a backward glance at an ongoing longitudinal study. In: Levitsky D, ed. Malnutrition, Environment and Behaviour. Ithaca: Cornell University Press, 1979, 219-37. 
70 Grantham-McGregor S, Walker S, Chang S. Nutritional deficiencies and later behavioural development. Proceedings of the Nutrition Society 2000; 59: 1-8.

71 Drewett R, Wolke D, Asefa M, Kaba M, Tessema F. Malnutrition and mental development: Is there a sensitive period? A nested case-control study. Journal of Child Psychology and Psychiatry, and Allied Disciplines 2001; 42: $181-7$.

72 Grantham-McGregor S, Powell C, Walker S, Chang S, Fletcher P. The long term follow-up of severely malnourished children who participated in an intervention programme. Child Development 1994; 65: 428-39.

73 McKay A, McKay H. Primary school progress after preschool experience: troublesome issues in the conduct of follow-up research and findings from Cali, Colombia Study. In: King K, Meyers R, eds. Preventing School Failure: The Relationship Between Preschool and Primary Education. Ottawa: International Development Research Center, 1983, 32-42.

74 Rutishauser I, Whitehead R. Energy intake and expenditure in 1-3 year old Ugandan children living in a rural environment. British Journal of Nutrition 1972; 28: $145-52$.

75 Torun B. Energy costs of various physical activities in healthy children. In: Schurch B, Scrimshaw N, eds. Activity, Energy Expenditure and Energy Requirements of Infants and Children. Lausanne: IDECG, Nestle, 1990, 139-83.

76 Spurr G, Reina J. Patterns of daily energy expenditure in normal and marginally undernourished school-aged Columbian children. European Journal of Clinical Nutrition 1988; 42: 819-34.

77 Torun B, Viteri F. Energy requirements of preschool children and effects of varying energy intakes on protein metabolism. In: Torun B, Young V, Rand W, eds. Food and Nutrition Bulletin. Protein energy requirements of developing countries: evaluation of new data. 1982; 5(Suppl.): 229-41.

78 Viteri F, Torun B. Nutrition, physical activity and growth. In: Ritzen M, Peria A, Hall K, Larsson A, Zetterberg A, Zettersrom R, eds. The Biology of Normal Human Growth. New York: Raven Press, 1981, 265-73.

79 Jahari A, Saco-Pollitt C, Husaini M, Pollitt E. Effects of an energy and micronutrient supplement on motor development and motor activity in undernourished children in Indonesia. European Journal of Clinical Nutrition 2000; 54: S60-8.

80 Levitsky D. Malnutrition and hunger to learn. In: Levitsky D, ed. Malnutrition, Environment and Behaviour. Ithaca, NY: Cornell University Press, 1979, 161-79.

81 Levitsky D, Strupp B. Malnutrition and the brain: changing concepts, changing concerns. Journal of Nutrition 1995; 125: $2245 \mathrm{~S}-54 \mathrm{~S}$.

82 Walker S, Powell C, Grantham-McGregor S, Himes J, Chang S. Nutritional supplementation, psychosocial stimulation and growth of stunted children: the Jamaican study. American Journal of Clinical Nutrition 1991; 54: 642-8. 